
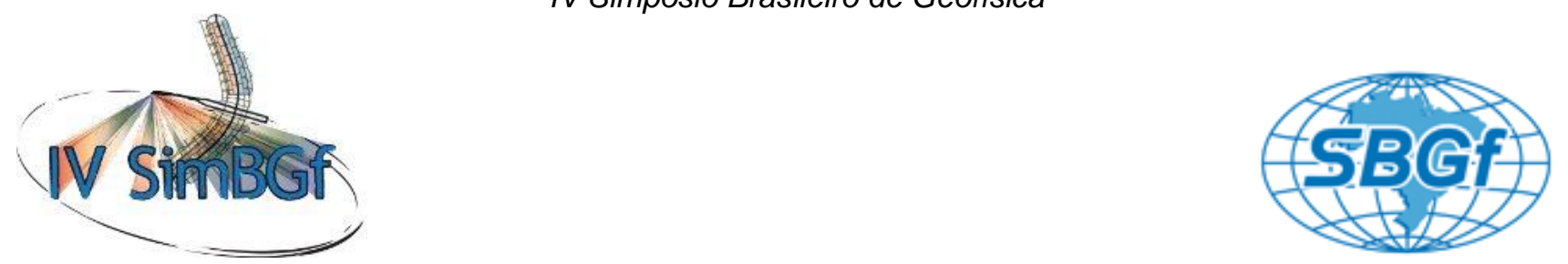

\title{
APLICAÇÃO DE GEOFÍSICA FORENSE NA BUSCA DE VESTÍGIOS DE PESSOAS DESAPARECIDAS NA GUERRILHA DO ARAGUAIA
}

Welitom Rodrigues Borges (Instituto de Geociências, UnB - welitom@unb.br)

Marcelo de Lawrence Blassay Blum (INC/DITEC, Departamento de Polícia Federal - blum.mlbb@dpf.gov.br)

Raimundo Mariano Castelo Branco (LGPSR, Instituto de Geociências, UFC - marianogcb@gmail.com)

Lúcia Maria Costa e Silva (Instituto de Geociências, UFPA - luciamcs@ufpa.br)

Milton José Porsani (CPGG, Instituto de Geociências, UFBA - porsani@cpgg.ufba.br)

Arno Brichta (CPGG, Instituto de Geociências, UFBA - brichta@cpgg.ufba.br)

Ailton Nascimento Amorim (LGPSR, Instituto de Geociências, UFC - amorimgeo@hotmail.com)

Nilo Costa Pedrosa Júnior (LGPSR, Instituto de Geociências, UFC - nilojuniorp@yahoo.com.br)

Vinícius Rafael Neris dos Santos (Instituto de Astronomia, Geofísica e Ciências Atmosféricas, USP - vinituning@gmail.com)

Luis Ricardo Cunha Braga (LGPSR, Instituto de Geociências, UFC - ricardobragas@hotmail.com)

José de Albuquerque Sobrinho (LGPSR, Instituto de Geociências, UFC - ze-albuquerque@hotmail.com

Péricles de Brito Macedo (Instituto de Geociências, UnB - macedo@unb.br)

Ernande Costa Santos (Instituto de Astronomia, Geofísica e Ciências Atmosféricas, USP - ernande@iag.usp.br)

Júlio Coelho Ferreira de Souza (INC/DITEC, Departamento de Polícia Federal-coelho.jcfs@dpf.gov.br)

Diógenes Leão Brasil (Instituto de Geociências, UFPA - dllbrasil@ufpa.br)

Magno Augusto Machado (Terracap/DF - magno.machado@terracap.df.gov.br)

Jackson Alves Martins (LGPSR, Instituto de Geociências, UFC - jackson geologia@yahoo.com.br)

Gustavo de Assunção Mello (ADIMB - gustavomello@adimb.com.br)

Copyright 2010, SBGf - Sociedade Brasileira de Geofísica

Este texto foi preparado para a apresentação no IV Simpósio Brasileiro de Geofísica, Brasília, 14 a 17 de novembro de 2010 . Seu conteúdo foi revisado pelo Comitê Técnico do IV SimBGf, mas não necessariamente representa a opinião da SBGf ou de seus associados. É proibida a reprodução total ou parcial deste material para propósitos comerciais sem prévia autorização da SBGf

\section{Resumo}

A identificação de inumações humanas no subsolo é uma prática pericial bastante utilizada no mundo todo, todavia sua localização é um desafio, quando não se dispõe de equipamentos para tal fim. Assim, qualquer equipamento que possibilite a localização de corpos ou restos humanos é de grande interesse na perícia médico legal. Este trabalho apresenta o panorama técnico dos trabalhos de geologia e geofísica efetuados com o intuito de cumprir a sentença judicial que objetiva localizar, recolher e identificar corpos de guerrilheiros e militares enterrados no evento conhecido como "Guerrilha do Araguaia".

\section{Introdução}

A Guerrilha do Araguaia foi um movimento de luta existente na região amazônica brasileira, ao longo do rio Araguaia, entre os fins da década de 60 e a primeira metade da década de 70. Criada pelo Partido Comunista do Brasil (PC do B), uma dissidência armada do Partido Comunista Brasileiro (PCB), tinha como o objetivo fomentar uma revolução socialista, a ser iniciada no campo, baseada nas experiências vitoriosas da Revolução Cubana e da Revolução Chinesa. Combatida pelo exército a partir de 1972, quando vários de seus integrantes já haviam se estabelecido na região há pelo menos seis anos, o palco das operações de combate entre a guerrilha e o Exército se deu onde os estados de
Goiás, Pará e Maranhão faziam fronteira. Seu nome vem do fato de se localizar às margens do rio Araguaia, próximo às cidades de São Geraldo e Marabá no Pará e de Xambioá, no norte de Tocantins.

O Grupo de Trabalho Tocantins (GTT) foi criado pela portaria 567, de 29/04/2009 (publicado no Diário Oficial n. 81, de 30 de abril de 2009), do ministro da Defesa, Nelson Jobim, para cumprir sentença da Primeira Vara Federal do Distrito Federal, que determinou à União a entrega dos restos mortais das pessoas envolvidas no evento conhecido como GUERRILHA DO ARAGUAIA.

A equipe do GTT foi composta por antropólogos forenses, antropólogos sociais, médicos legistas, geólogos e geofísicos, sob a coordenação do Ministério da Defesa, com o apoio logístico do exercito.

\section{Metodologia}

O GTT compôs uma ouvidoria interna que ficou responsável pela obtenção de informações com ex-guias, ex-militares, ou pessoas locais que indicassem áreas onde possivelmente ocorreram inumações de pessoas envolvidas na guerrilha.

Posteriormente a equipe era conduzida a estes locais indicados, com o objetivo de verificar qualquer evidencia superficial que indicasse uma inumação local. No local, a equipe técnica decidia, a partir da analise dos relatos e das evidencias em superfície, se realizava os trabalhos 
de georeferenciamento, geologia/geofísica e antropologia forense. Caso a equipe resolvesse realizar os trabalhos no local visitado, era definido um polígono cuja área era definida a partir das informações obtidas.

A equipe do georeferenciamento do exercito realizava assim o levantamento planialtimetrico de precisão em todo o polígono. A Figura 1 ilustra o resultado de um mapa topográfico obtido em um polígono estudado. A partir da delimitação dos vértices do polígono, a equipe de geologia/geofísica (EGG) iniciava os trabalhos de campo.

A EGG do GTT foi composta nas etapas de campo por Docentes, Peritos em Geologia e Geofísica, Geólogos, Geofísicos e Técnicos de Instituições Nacionais. Cada EGG foi composta por três ou quatro integrantes. No ano de 2009 foram realizadas 5 etapas de campo. $\mathrm{Na}$ primeira etapa a equipe de geologia/geofísica foi composta por duas equipes; na segunda por uma equipe; e nas terceira, quarta e quinta etapas por três equipes de geologia/geofísica. Cada equipe dispunha de um equipamento de radar de penetração no solo (ground penetrating radar - GPR), do Modelo SIR-3000 (fabricado pela empresa Geophysical Survey Systems, Inc.) acoplado a uma antena blindada com freqüência central de $400 \mathrm{MHz}$ e roda odométrica. Os equipamentos utilizados pertencem: ao Laboratório de Geofísica de Prospecção e Sensoriamento Remoto (LGPSR) da Universidade Federal do Ceará; do Laboratório de Geofísica Aplicada e Equipamento de Campo do Instituto de Astronomia, Geofísica e Ciências Atmosféricas (IAG/USP); e do Instituto Nacional de Criminalística (INC/DITEC, Departamento de Polícia Federal). O INC/DITEC também utilizou um detector de metais do tipo caça-minas em certas situações para procurar artefatos metálicos (cartuchos, projéteis, entre outros) do evento histórico.

Cada equipe efetuou a aquisição de dados em uma área distinta, possibilitando, deste modo o imageamento GPR em até três áreas simultaneamente.

Os dados de GPR foram adquiridos através da técnica do afastamento comum (commom offset), o que permite a visualização em tempo real dos refletores do subsolo. As imagens de radar do subsolo foram obtidas ao longo de perfis equiespaçados em 0,5 metro e, por vezes, 0,2 ou 0,1 metro dependendo do alvo pesquisado. A Figura 2 ilustra um mapa mostrando a disposição das linhas de GPR em um polígono.

Após a aquisição dos dados, os mesmos foram processados em softwares específicos para dados de GPR (software ReflexW, versão 5.0 - licença do LGPSR/UFC e do INC/DITEC/DPF); e software RADAN, versão 6.5 - licença do IAG/USP). A rotina de processamento consistiu em conversão de formato do arquivo, ajuste do tempo zero, filtros temporal (dewow e passa-banda), ganho (decaimento de energia), migração em tempo (fk migration - Stolt), conversão em profundidade (velocidade constante) e correção topográfica. Para a obtenção da velocidade eletromagnética no meio, era enterrada uma cabeça de picareta com $0,05 \mathrm{~m}$ de diâmetro a $0,50 \mathrm{~m}$ de profundidade na lateral da área. Sobre este artefato era efetuado um pequeno perfil GPR e conhecendo-se a profundidade real do mesmo, bem como o evento hiperbólico relacionado à picareta, obtinha-se a velocidade de propagação da onda eletromagnética no meio $(v)$ usando-se a Equação 1.

$$
v=\frac{2 h}{t}
$$

Sendo $h$ a profundidade do alvo, e $t$ o tempo duplo de trânsito da onda eletromagnética no meio. A velocidade era calculada e utilizada na inversão dos dados (tempo para profundidade). A Figura 3 mostra um local onde foi enterrada a picareta, bem como o perfil GPR obtido sobre a mesma.

As etapas de processamento foram aplicadas de acordo com as características dos dados e dependem, fundamentalmente, do intérprete. Uma vez escolhido o fluxo de processamento para uma seção GPR, o mesmo é aplicado às outras seções de modo homogêneo.

Além do processamento bidimensional, o conjunto de dados GPR realizado com a mesma antena era georreferenciado e interpolado, possibilitando a geração de um novo conjunto de dados, agora com informação tridimensional (3D) do subsolo para a área georreferenciada.

\section{Resultados}

Os resultados de GPR foram analisados através de seções 2D individuais, bem como através de cortes em profundidade (depth slices) efetuados no conjunto 3D dos dados, produzindo diversos mapas de amplitude do sinal. A Figura 4 mostra um conjunto 3D de dados GPR, bem como seções 2D e cortes em profundidade que compõem o conjunto 3D.

As análises e interpretações dos resultados de GPR foram efetuadas com base nos padrões anômalos típicos de ossos humanos bem descritos na literatura (Strongman, 1992; Isaacson, et al, 1999; Hammon III, et al, 2000; Dupras, et al, 2006; Nascimento, 2009). A Figura 5 mostra alguns padrões anômalos onde foram realizadas escavações na busca de vestígios humanos.

Depois de identificadas as anomalias, as mesmas foram georeferenciadas através de coordenadas tridimensionais (X, Y e Z).

Depois da marcação do alvo no solo, procedia-se a escavação. Para tanto, era delimitado um retângulo com $2 \times 1,2$ metros, coincidindo o maior eixo do alvo detectado pelo GPR com o lado maior da delimitação no solo. Os sítios retangulares foram divididos transversalmente em três partes, sendo que as centrais mediam 0,8 x 1,2m e as das extremidades, $06 \times 1,2 \mathrm{~m}$. Na maior parte das vezes, apenas as áreas centrais foram escavadas, uma vez que eram as que coincidiam com o alvo apontado pelo GPR. As escavações foram realizadas por uma equipe de preparação do terreno com 
Borges, WR; Blum, MLB; Branco, RMC; Silva, LMC; Porsani, MJ; Brichta, A; Amorim, AN; Pedrosa Jr, NC; Santos, VRN; Braga, LRC; Albuquerque, J; Macedo, PB; Santos, ECS; Souza, JCF; Brasil, DL; Machado, MA; Martins, JA; Mello, GA.

ferramentas usuais - enxadas, pás e picaretas - até dez centímetros acima dos alvos indicados. A partir desse ponto, a Equipe de Antropologia, sem adentrar os sítios, continuava as escavações, com ferramentas mais delicadas e precisas, até que os alvos fossem atingidos. As perturbações encontradas então eram minuciosamente examinadas e fotografadas e seus achados discutidos com a Equipe de Geologia, para só então decidir-se pelo encerramento das escavações. A Figura 6 registra o trabalho da equipe de antropologia forense durante a escavação do solo nos locais onde ocorreram anomalias de GPR.

Verificou-se que as anomalias de GPR representaram pequenas variações no solo, cavidades de pequenos animais, pequenos blocos de rocha, raízes e, por vezes, lixo enterrado. A Figura 7 mostra alguns materiais encontrados durante a escavação do solo nos locais onde ocorreram as anomalias de GPR.

\section{Discussão e Conclusões}

Ao total a equipe do GTT realizou trabalhos de geofísica em 21 áreas, totalizando uma total de 28.452,50 $\mathrm{m}^{2}$ de GPR 3D. Nestas áreas foram perfurados 64 pontos onde - GPR apresentou padrões semelhantes a áreas escavadas. Todavia, os padrões anômalos de GPR encontrados nas áreas estudadas, após as escavações, não representaram áreas de inumações humanas.

O fato de não terem sido encontrados restos humanos nas escavações pode ser explicado por vasto rol de razões. $O$ aspecto fundamental é o longo tempo decorrido entre o episódio da guerrilha e a presente missão. Este lapso temporal pode ter contribuído para o não encontro dos restos mortais procurados devido à mudança radical da paisagem, por obra da natureza e principalmente pela mão humana, dificultando a localização precisa, pelos colaboradores, dos locais de inumação; outro aspecto muito importante seria o processo de decomposição dos corpos que, no clima quente e úmido da área do conflito, provavelmente se fez de forma mais acelerada; por fim, o tempo certamente contribuiu para a diminuição da clareza da memória dos agentes envolvidos nos fatos.

Outro fator complicador reside no fato de que, conforme apurado, alguns corpos não devem ter sido propriamente inumados e sim apenas cobertos com solo orgânico superficial e folhagens, ou simplesmente deixados insepultos. Nestes casos, tais corpos dificilmente deixariam resquícios, visto que poderiam ter sido totalmente consumidos pela ação do tempo, pela ação de animais, inclusive com a remoção dos mesmos do local final de repouso, ou levados por águas pluviais nos terrenos mais íngremes.

Apesar de todos os fatores físicos e políticos que dificultam as buscas no Araguaia, a equipe de Geologia e Geofísica se compromete a dar total apoio a qualquer entidade governamental que procure recuperar os vestígios de pessoas que participaram do evento conhecido como Guerrilha do Araguaia.

\section{Agradecimentos}

Agradecemos a 23ํㅡㄹ Brigada de Selva pelo apoio logístico em todas as etapas de campo, em especial ao Gen. Mario Lucio Alves de ARAUJO, Cel. Alfredo Alexandre de MENEZES Júnior, Maj. Paulo Cézar CROCETTI, Sgt. Robson Pereira ÁLVARES e ao Sgt. Anderson ADOLFO Scipião dos Santos.

Ao Ministério da Defesa, representado pela coordenação de campo do GTT, Sr. Edmundo Theobaldo Müller Neto e Sr. Sávio Luciano de Andrade Filho.

A toda equipe da empresa Algemista pelo auxilio na escavação dos pontos anômalos.

A toda equipe de antropologia forense do GTT, principalmente aos médicos legistas Ricardo Frade, Elvis Adriano e Jeferson Evangelista.

A Tereza, do Ministério da Defesa, pelo registro fotográfico de todas as etapas de campo do GTT.

\section{Referências}

DUPRAS, D.; SCHULTZ, J.; WHEELER, S.; WILLIAMS, L. 2006. Forensic Recovery of Human Remains: Archaeological Approaches. Taylor \& Francis Group Publishers, Boca Raton, Florida, USA, 232pp.

HAMMON III, W. S.; McMECHAN, G. A.; ZENG, X., 2000. Forensic GPR: finite-difference simulations of responses from buried human remains. Journal of Applied Geophysics, Vol. 45: 171 - 186.

ISAACSON, J.R.; HOLLINGER, E.; GUNDRUM, D.; BAIRD, J. 1999. A Controlled Archaeological Test Site Facility in Illinois: Training and Research in Archaeogeophysics. Journal of Field Archaeology, Vol. 26(2):227-236.

NASCIMENTO, W.G. 2009. Investigação geofísica ambiental e forense nos cemitérios do Bengui e do Tapanã (Belém-PA). 2009. Dissertação (Mestrado em Curso de Pós Graduação Em Geofísica), UFPA, 150p.

STRONGMAN, K. B., 1992. Forensic applications of ground penetrating radar. In: Ground Penetrating Radar, ed. J. Pilon, Geological Survey of Canada, Paper 90-4, p. 203-211. 


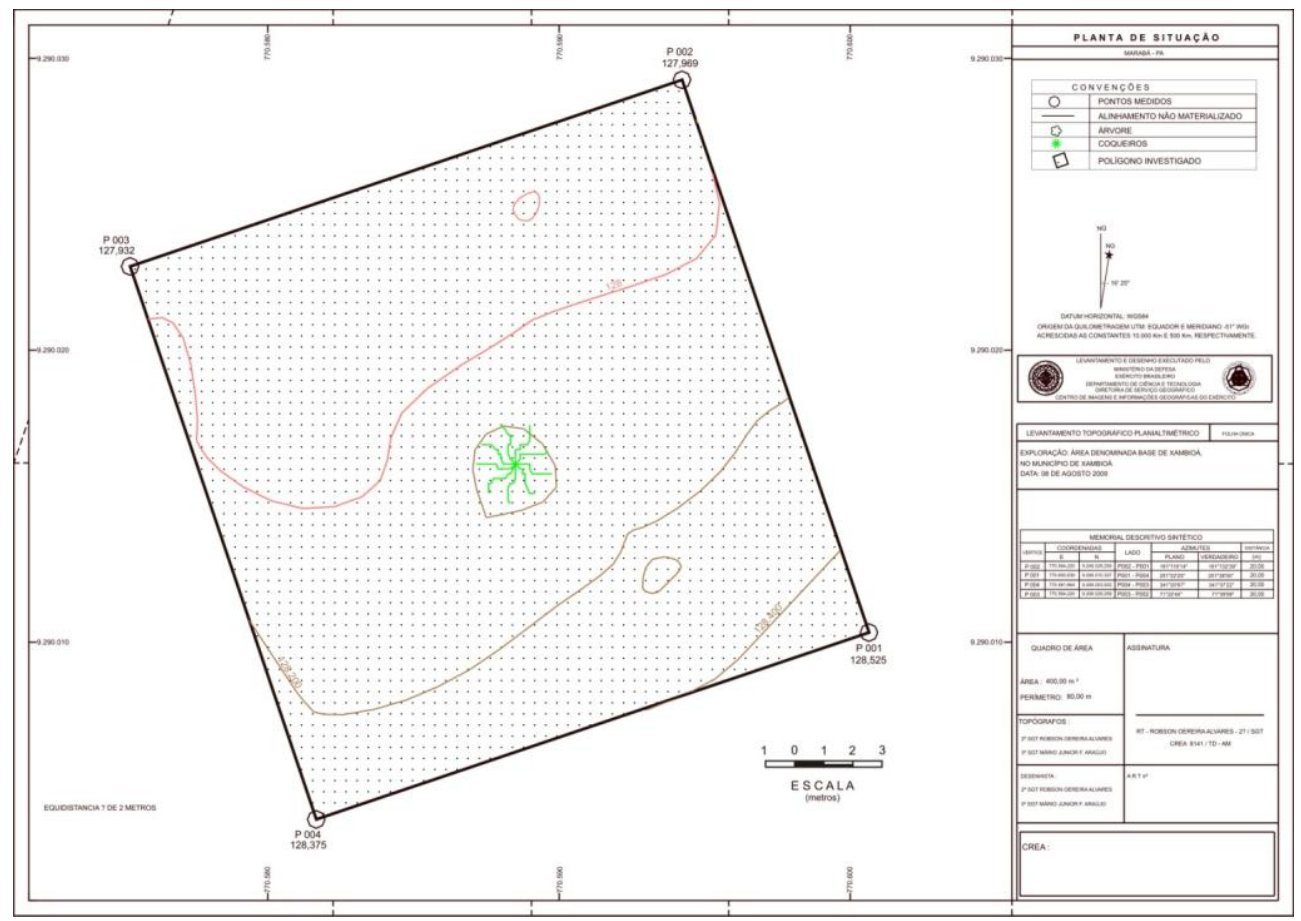

Figura 1 - Exemplo de Mapa de localização de polígono georeferenciado para estudos de antropologia forense do Grupo de Trabalho Tocantins. Área da Base de Xambioá I, Município de Xambioá - TO.

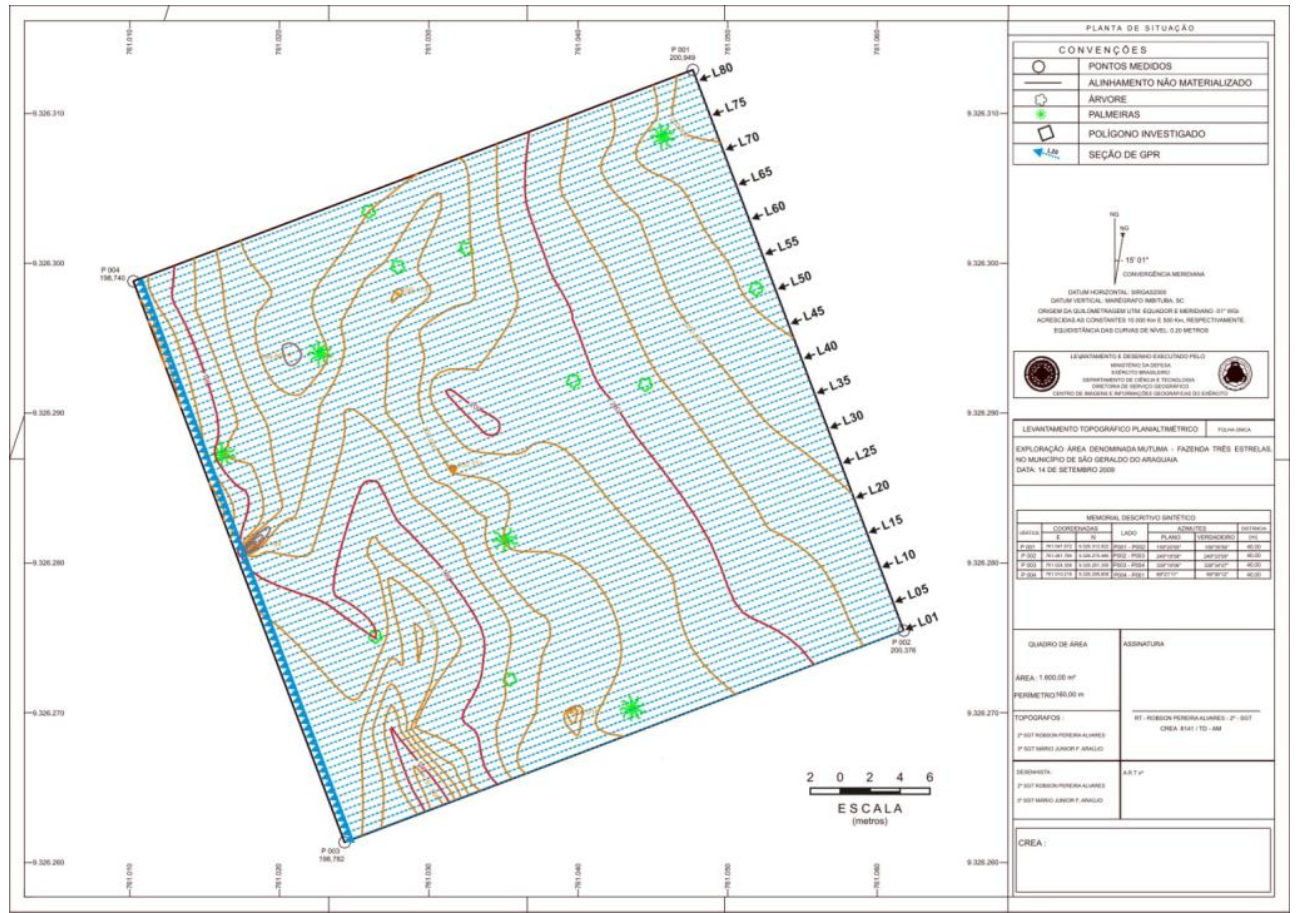

Figura 2 - Exemplo de Mapa de disposição das linhas de GPR efetuadas em um polígono estudado pelo Grupo de Trabalho Tocantins. Área de Mutuma, Fazenda Três Estrelas, Município de São Geraldo do Araguaia - PA. 


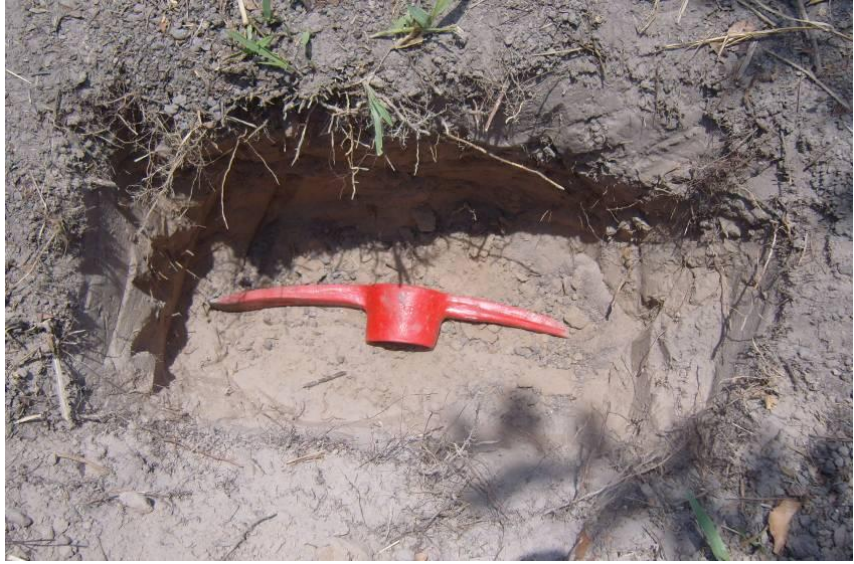

(a)

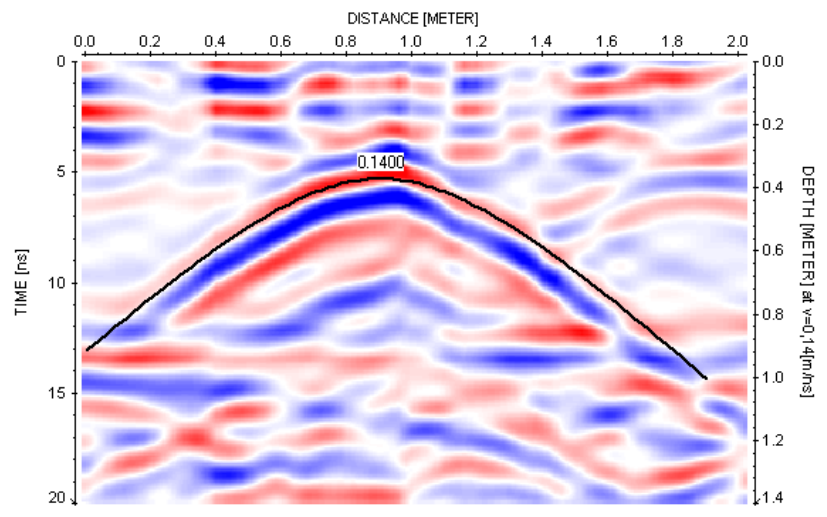

(b)

Figura 3 - (a) Foto de uma cabeça de picareta enterrada no subsolo para a calibração da velocidade da onda eletromagnética do GPR. (b) Perfil GPR realizado sobre a picareta enterrada na área do Córrego Mutuma. Velocidade de 0,14 $\mathrm{m} / \mathrm{ns}$ obtida através de ajuste hiperbólico.
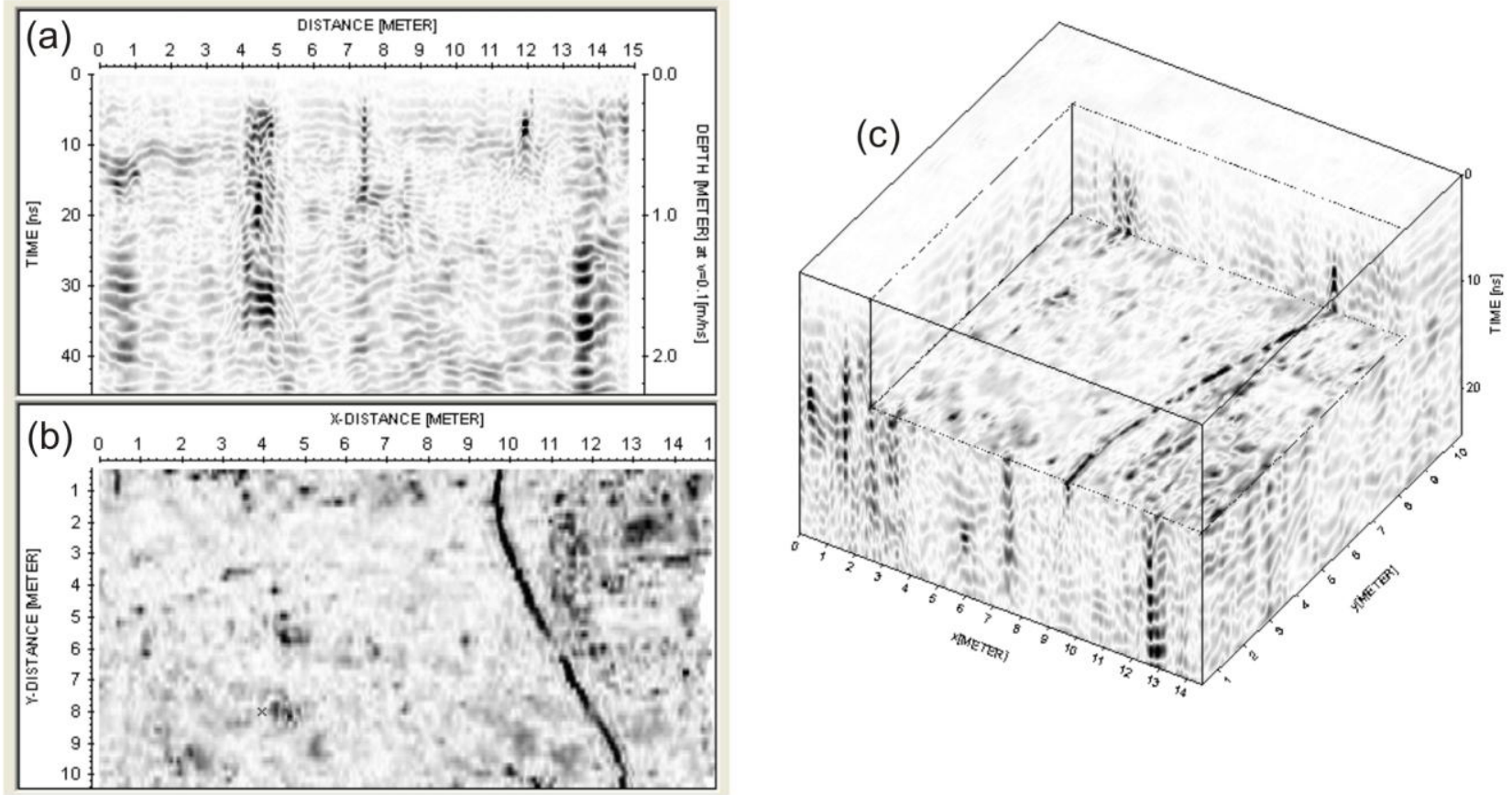

Figura 4 - (a) Seção GPR 2D de uma área investigada. (b) Corte em profundidade (depth slice) em um bloco 3D. (c) Bloco GPR 3D composto através da interpolação de seções 2D. 

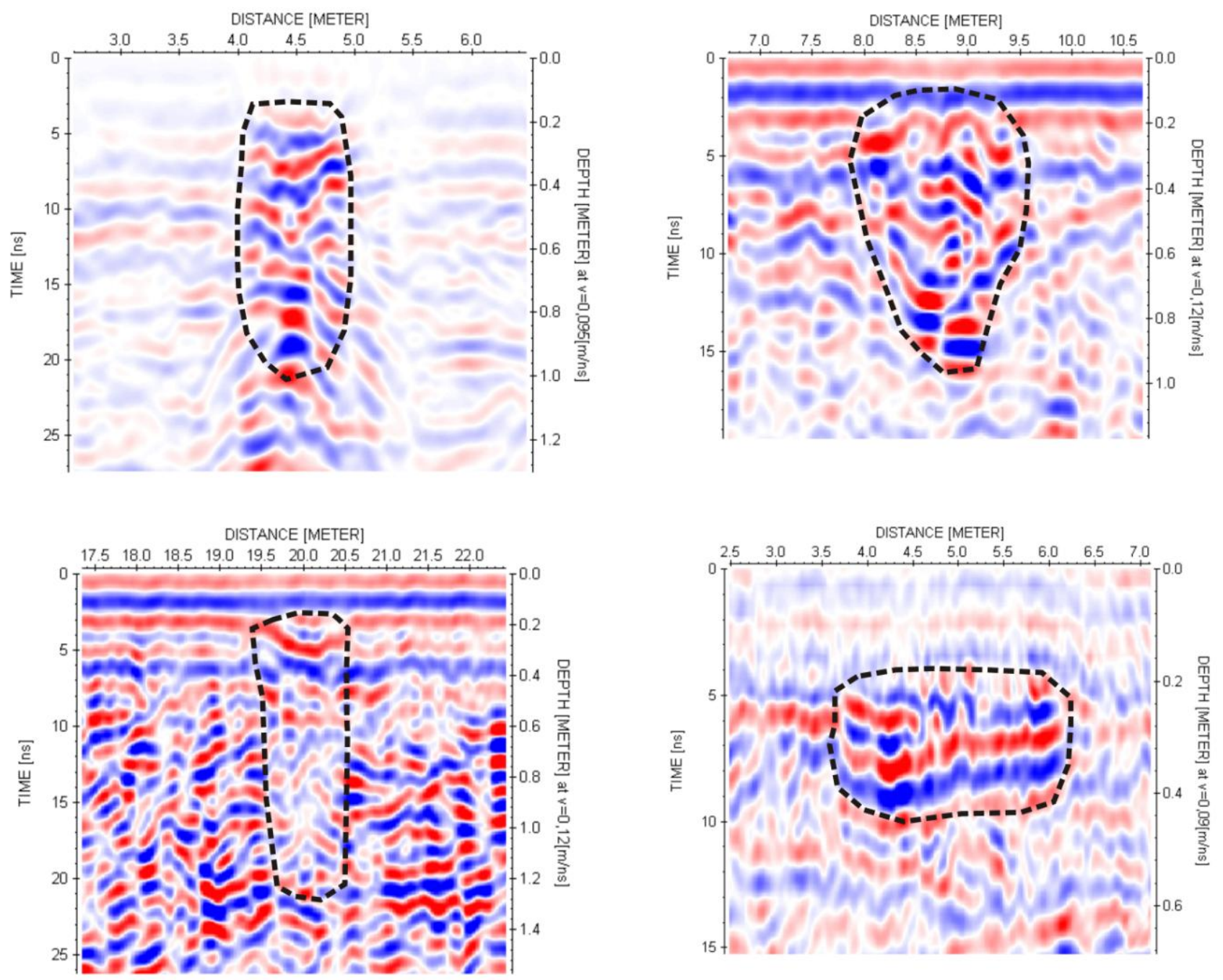

Área de possível inumação

Figura 5 - Parte de seções de GPR mostrando os padrões anômalos que direcionaram as escavações. 

Mello, GA.
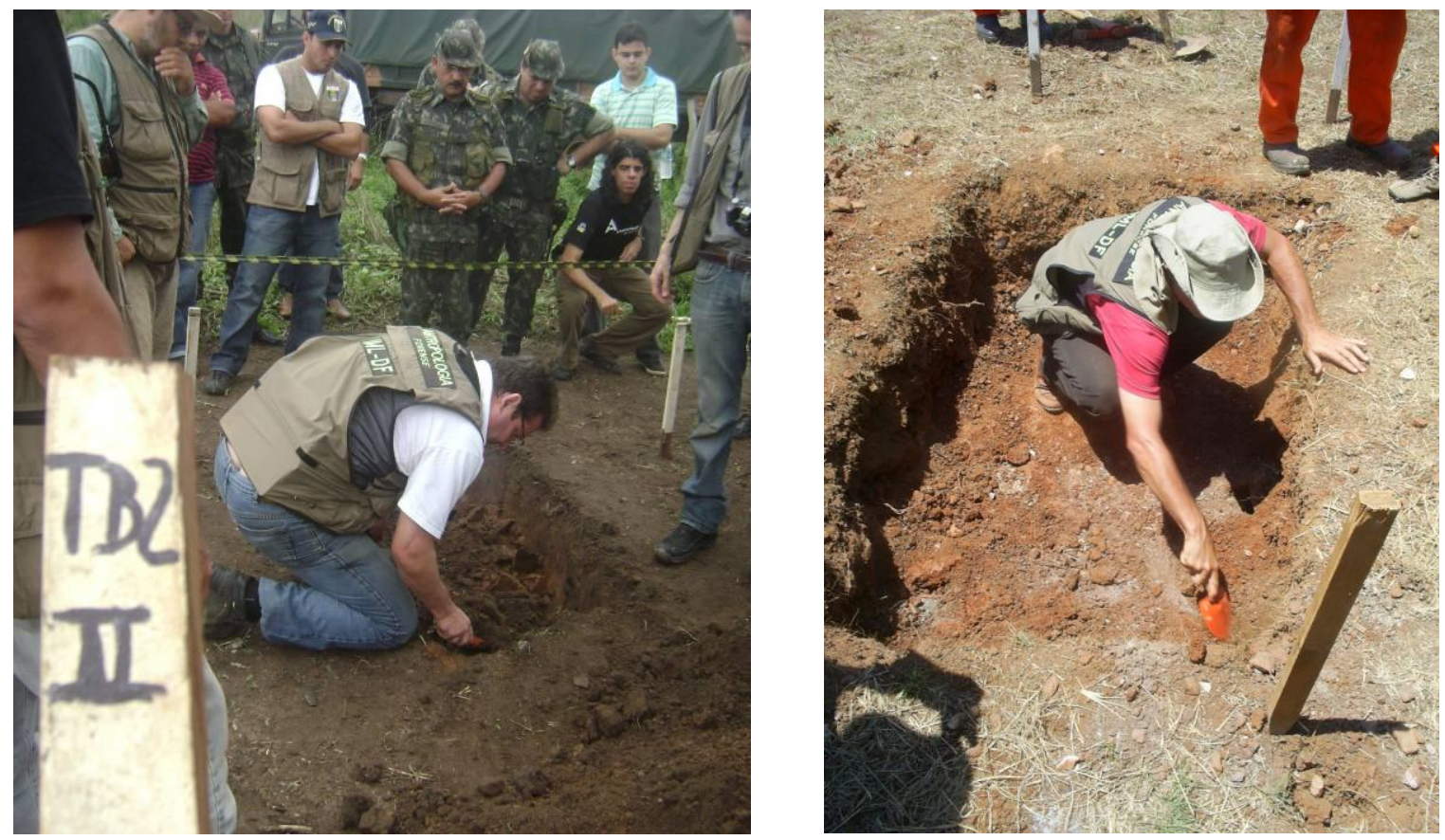

Figura 6 - Fotos das equipes de antropologia forense realizando escavações nos pontos anômalos indicados pela equipe de geologia e geofísica do GTT.
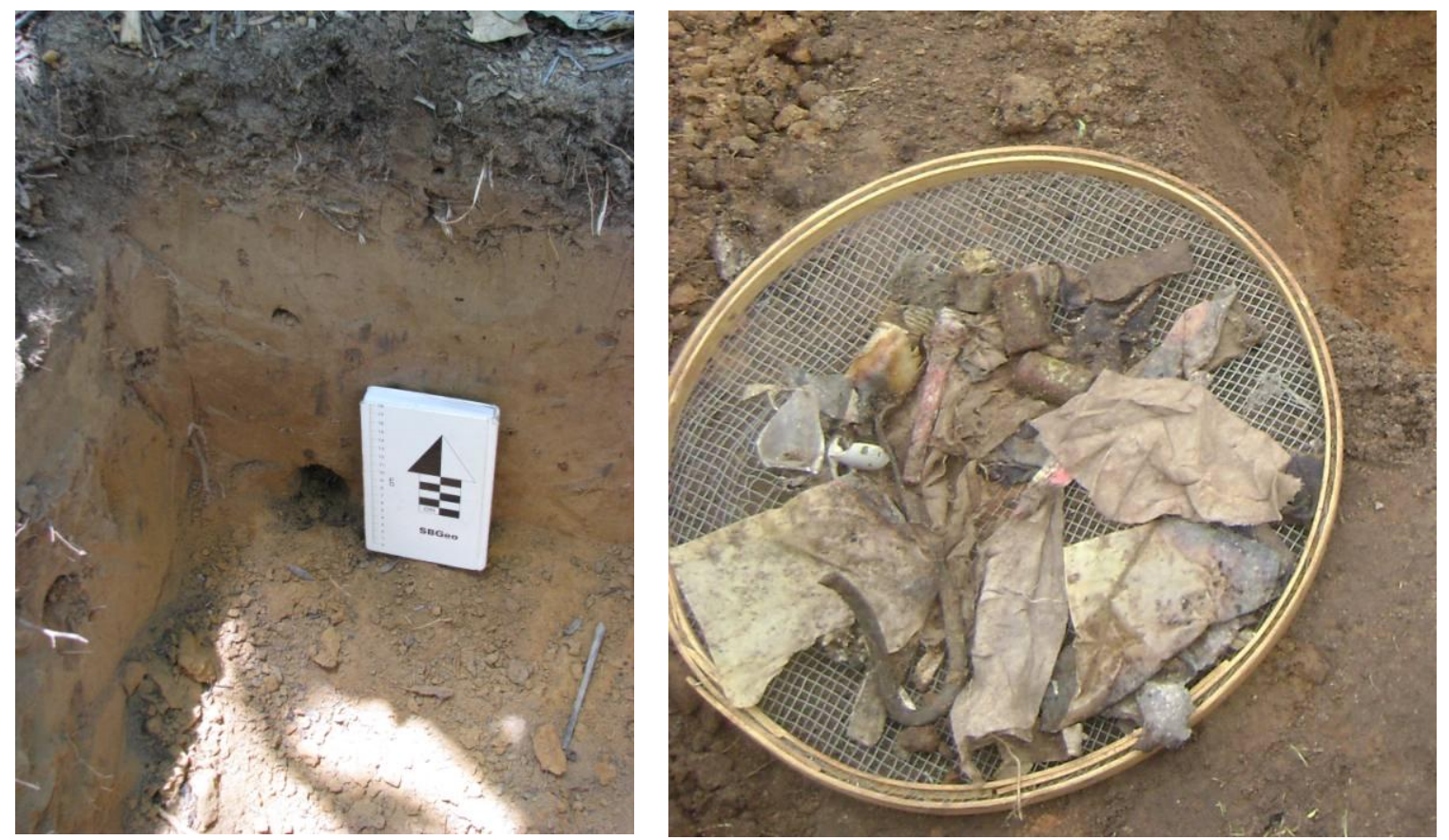

Figura 7 - Fotos dos alvos encontrados pela equipe de antropologia forense durante as escavações dos pontos anômalos. 